\title{
The Analysis of Job Related Stress on Teachers of Junior High Schools and High Schools of Kermanshah Province
}

\author{
Habib Soleimani \\ University of Isfahan, Iran \\ Email: h181352@yahoo.com \\ Ahmad Moinzadeh \\ University of Isfahan, Iran \\ Email: moin@ fgn.ui.ac.ir
}

\begin{abstract}
This study has been designed with the purpose of analyzing factors causing job-stress and the amount of stress prevalence in teachers. In this research 150 teachers were selected according to a multi stage cluster sampling. This study used a 66 questioning scale called TSS scale ( Kyriacou and Sutcliffe, 1978). Some correlational analyses and independent sample t-tests were used. Findings indicated that job-related stress of men and women do not differ significantly. No correlation was also observed between job- related stress and marital status, level of education. However, in the subscales of socioeconomic difficulties and restricted time issues there was a significant difference between single and married teachers on English language.
\end{abstract}

Index Terms - stress, job satisfaction, marital status, level of education, employment condition, restricted time

\section{INTRODUCTION}

Sometimes human life influenced by some factors gets into a psychological tension and this matter provides some solutions and methods for getting away from those tensions. Psychological pressure or "stress" is one of the key factors of threat in nowadays life (Mitchell, 2005). Stress is a collection of general reactions of human being to inner and outer incompatible and unpredictable factors so that whenever the human's adaptation to inner and outer factors are removed, stress will appear. (Rezaee, 2002) and Nowadays only a few people are not familiar with this definition because there are a lot of people who talk about the pressures of work and life. So we can say that tension is a part of a person's normal and everyday life. Furthermore evidence shows that problems resulting from stress generating events have increased in the $20^{\text {th }}$ century especially in western advanced countries to the point where some commentators call our age the "age of stress" (Kyriacou, \& Sutcliffe, 1978a).

Each person faces a big amount of stress sources in his/her life in a way that it influences him/her from different aspects. These factors can result from the environment for example different accidents, life events, death and war or they can stem from internal aspects and characterization such as contradictions, failures, shortages, privations, psychological pressures resulting from job conditions are stress generating and are the sub-sets of environmental factors and are related to the working side of a person's life (Rasooli, 2003).

The reflection and demonstrations of stress can appear in a person as lack of health, depression, anxiety, lack of competence, weak mentality, disliking work, constant absence, job dissatisfaction, not being punctual and complaining about the people in charge (Selye, 1993 cited in Mitchell, 2001). According to some vast international researches (Mitchell, 2001) on the field of stress and job satisfaction of teachers, the mutual relationship between these two subjects has been confirmed and the results show that high level stress provides dissatisfaction of jobs in people and this dissatisfaction plays a role in decreasing extra stress and functioning. Here there is the need to mention that job satisfaction on the one hand is a symmetrical result of factors such as individual specifications (necessity, affection, motivation) and on the other hand jobbing characteristics (type of job, job environment) (Kyriacou, 2001).

Therefore it seems that stress, with its high influence on a person's competence and functioning, also influences the amount of satisfaction. Teachers who are under the burden of teaching and training are not only like other people, exposed to stress factors but also it seems that this exposure is more in teachers because they face a job which is troublesome, difficult, has a high responsibility and a high amount of work and low amount of welfare facilities and it is natural that the intensity of pressure frequency generating from this job compared to other jobs is more and consequently this matter influences the amount of satisfaction they have towards their profession.

\section{A. Statement of the Problem}


The studies which have been done regarding stress generating factors have some complications because on one hand the concept of stress is viewed from both positive and negative point of view and on the other hand stress is also a mental phenomenon. Therefore, different views about stress have been proposed in order to be able to measure its various effects.

Generally, in different cultures different definitions of stress are given such as the definitions given in Lewis (1999). In addition, Kyriacou and Sutcliffe (1978) have defined stress as an answer to undesirable feelings such as failure, anxiety, aggression and depression that generate from the job of teaching. The relationship of these work related stress factors with mental health and job satisfaction will be investigated in this research.

This point should be mentioned that stressors exposed to a person from the area of education and training is not all negative factors (Dolati, 2002). The stress generating factors in education and training environments that have been collected in researches are: contradiction between colleagues, the condition of the working environment, students unsuitable behavior, lack or low motivation for studying in students, high amount of work in a low amount of time and low economic and social condition. (Kyriacou and Stcliffe, 1978). Kyriacou and Sutcliffe (1978) believe that the behavioral gesture of a person, the focus of control and the method of opposing to stress are influential factors in the adjustment of the relationship between job satisfaction and stress and people who have an outside focus control, are faced with more stress.

Recently a great amount of concerns have been observed among those involving in educational affairs about mental health of teachers in Iran because high stress is harmful for their health and capabilities which in turn can affect their way of teaching, personal life, and most important of all the students; therefore, detecting stress generating factors among teachers and reducing and probably removing these factors are among the challenges of Ministry of education.

According to Kyriacou and Sutcliffe model of teacher stress (1978a) understanding stress, results from the teacher's inference, the course of which is as follows: 1. He is exposed to a request. 2. He cannot fulfill those requests or has problems in fulfilling them, and 3. Consequently, his psychological and physical health is threatened.

In this regard Habibi (2007) indicated that teachers were most satisfied with moral values, creativity, activity, variety and application of their abilities and were least satisfied with policies of educational system, development and jobsafety. This study is in line with Rostami Nia (2000).

Kyriacou and Sutcliffe (1978) mention the following six factors as the main causes of stress: 1. Excessive load of work. 2. Lack of professional development. 3. Not having a good social position. 4. Inappropriate relations among colleagues. 4. Large number of students in class and their not having enough motivation for education 6. Low salary.

Stress of teachers threatens their psychological health, decreases their efficiency, causes job dissatisfaction among them and leads them to cancel their classes (Levinson, 1999).

Furthermore, stress can also have the consequence of negative attitudes towards job, students, colleagues and finally educational organization (Pisanti, Galliards and Razino, 2003). Therefore, teachers are exposed to stress and stress generating factors from different sources.

An overview of different studies concerning psychological stress indicates that feeling low social status, shortage of educational facilities, students misbehavior, mismatch between the volumes of course books and hours dedicated to covering the materials, lack of well-defined criteria for evaluating efficiency of teachers are among the stress generating sources for teachers (Newman \& Beehr,1979; Shinn, Rosario, Morch \& Chestnut, 1984).

\section{B. Significance and Justification of the Study}

According to what was mentioned above, a great amount of concern has come into existence among the commentators of education and learning because high levels of stress is harmful for their health and the output of their job and it can influence the way they teach, their personal life and most important of all the students. Thus, detecting job related stress factors and decreasing them is one of the main challenges of Ministry of education in Iran.

The Present study mainly has the purpose of detecting job related stress factors and investigating increase of stress among teachers of English language in junior high schools and high schools of Kermanshah province. No Studies have been done in this regard in Kermanshah province among teachers of English. By detecting the stress generating factors, there would be possibility of giving some recommendations for having a better mental health among teachers of English. After detecting the stress generating factors, the counseling center would be able to hold counseling sessions, educational and life skill workshops to familiarize teachers with ways of opposing stress.

\section{RESEARCH QUESTIONS}

1. Is there any significant difference between male and female teachers of English regarding stress amount in Kermanshah province?

2. Is there any statistically significant difference between single and married teachers of English concerning jobrelated stress in Kermanshah province?

3. Is there any significant difference between single and married teachers of English language for job-related stress in the fragment scale of socioeconomic difficulties in teachers of English language in Kermanshah province?

4. Is there any significant difference between single and married teachers of English language concerning job-related stress in the subscale of restricted time on them? 
5. Is there any statistically significant correlation between employment conditions and job-related stress among teachers of English in Kermanshah province?

6. Is there any statistically significant correlation between single and married teachers of English language concerning job-related stress in the subscale of restricted time on them?

\section{METHOD}

\section{A. Participants}

The participants of this study have been teachers of English in junior high schools and high schools of Kermanshah in the educational year of 2008-2009. The participants have been selected according to multi stage cluster sampling. The population (Kermanshah province) was divided into three geographical areas, north and south as one area, centre and east each as one area. Due to the vastness of the Kermanshah province, it has been defined under three clusters and from each cluster a big and a famous city and from each big city 3 girls' schools and 3 boys' schools were chosen. The sample equals 150 people.

\section{B. Instrumentation}

To measure the amount of stress in teachers a questionnaire which included 66 questions called TSS scale, made by Kyriacou and Sutcliffe (1978) was used. Its Cranbach alpha coefficient validated by Habibi (2007) and the amount was 0.81 .

\section{Data Analysis}

This is a causal-correlational and ex-post facto design study. Because there were two kinds of nominal and interval data, some independent sample t- tests and some correlation coefficient were computed.

\section{RESUlTS AND FINDINGS}

To study the results, the numbers and figures relating to the research questions are given in the tables below. Regarding the first research question about the differences of stress amount in men and women teachers, the $\mathbf{t}$ - test has been used for independent samples. This test shows that there isn't any noticeable difference between men and women in terms of job stress.

TABLE1

T TEST FOR THE MEAN DIFFERENCE OF JOB RELATED STRESS OF MEN AND WOMEN

\begin{tabular}{|c|c|c|c|c|c|}
\hline Gender & Mean & Standard deviation & Degree of freedom & t observed & P-value \\
\hline Women & $153 / 65$ & $23 / 27$ & 182 & 0.34 & 0.73 \\
\hline Men & $154 / 78$ & $21 / 80$ & & & \\
\hline
\end{tabular}

In table 2 the results relating to the independent t-test for the difference between single and married teachers and job stress, the case of the second research question has been given. The observed t score is 1.68 and it's only close to significant level. The results indicate that there is a difference between single and married teachers regarding job-related stress though nonsignificant, it is noticeable.

TABLE 2

INDEPENDENT SAMPLE T - TEST TO COMPARE JOB RELATED STRESS OF SINGLE AND MARRIED TEACHERS

\begin{tabular}{|l|l|l|l|l|l|}
\hline \multicolumn{1}{|c|}{ INDEPENDENT SAMPLE T - TEST TO COMPARE JOB RELATED STRESS OF SINGLE AND MARRIED TEACHERS } \\
\hline Marital status & Mean & Standard deviation & Degree of freedom & T observed & \\
\hline Single & & & & $1 / 68$ & \\
\hline Married & $151 / 67$ & $21 / 75$ & 180 & & \\
\hline
\end{tabular}

Regarding the third research question, table 3 indicates that in the fragment scale of social-economic difficulties, the difference between single and married teachers is significant, in other words in the fragment scale of social-economic difficulties in terms of stress there is a significant difference between single and married teachers.

TABLE3

T TEST FOR THE MEAN DIFFERENCE OF JOB RELATED STRESS OF SINGLE AND MARRIED TEACHERS IN THE FRAGMENT SCALE OF SOCIOECONOMIC DIFFICULTIES

\begin{tabular}{|l|l|l|l|l|l|}
\hline Maritat status & Mean & Standard deviation & Degree of freedom & T & P \\
\hline Single & $47 / 51$ & $8 / 39$ & 185 & $2 / 61$ & $0 / 010$ \\
\hline Married & $50 / 96$ & $8 / 88$ & & & \\
\hline
\end{tabular}

Table 4 which is related to the fourth research question shows that on the small scale of restricted time on teachers causing stress, there is a difference between single and married teachers as regards to time related stress. Restricted time causes more stress in married teachers. 
TABLE 4

T TEST FOR THE MEAN DIFFERENCE OF OVERALL WORK RELATED STRESS BETWEEN SINGLE AND MARRIED TEACHERS AND THE EFFECT OF RESTRICTED TIME ON THEM.

\begin{tabular}{|l|l|l|l|l|l|}
\hline marital status & Mean & Divergent from norm & Degree of freedom & T & P-value \\
\hline Single & $18 / 83$ & $3 / 45$ & 185 & $2 / 85$ & $0 / 005$ \\
\hline Married & $20 / 44$ & $4 / 02$ & & & \\
\hline
\end{tabular}

Table 5 concerning research question number 5 indicates that there is no significant correlation between the degree of education and work related stress. The correlation is such that examination on a sub scale is made impossible.

TABLE 5

COEFFICIENT OF CORRELATION BETWEEN LEVEL OF EDUCATION AND WORK RELATED STRESS

\begin{tabular}{|l|l|l|l|}
\hline \multicolumn{2}{|c|}{ Job related stress } & Education level & Level of significance \\
\hline Education & 0.007 & 1.000 & 0.92 \\
\hline job related stress & 1.000 & 0.007 & \\
\hline
\end{tabular}

The data in table 6 shows that there is no significant correlation between the conditions of employment and overall work related stress. Nonetheless, the examination of sub scales seems necessary. The test was carried out and the findings for the last research question showed that the conditions of employment had a negative correlation with sub scale stress related to student's behavioral problems. However if the conditions of employment improve, it would seem that stress related to student's behavioral problems increases.

TABLE 6

CORRELATION BETWEEN EMPLOYMENT CONDITIONS AND JOB RELATED STRESS

\begin{tabular}{|l|l|l|l|}
\hline & Job related stress & Employment conditions & Level of significance \\
\hline Employment conditions & 0.082 & 1.000 & 0.263 \\
\hline job related stress & 1.000 & 0.082 & \\
\hline
\end{tabular}

\section{DisCUSSION AND CONCLUSION}

The aim of this study was analyzing factors causing job-stress and the amount of stress prevalence in high schools and junior high schools teachers of English in Kermanshah province using a questionnaire called TSS scale. The researcher posed six research questions which led the research.

The analysis of research findings indicates that there is no significant difference in the level of work related stress between men and women teachers in Kermanshah; they experience the same level of stress. This is in disagreement with the findings of Booney, Miller, Humphreys, and Reynolds (1989) who believe that work related stress for men is much higher than that of women's work related stress. The difference in the outcome of these findings can be a result of them taking into account jobs as a whole entity and not just the individual job of teaching. From another point of view, different variables may have been used in the research; this could also be another reason for the discord between the two different outcomes. Another point to be mentioned is the fact that in the culture of this region, all domestic work rests on the shoulders of the women as opposed to western cultures where there is a greater sharing of general household work. As a result women's career coupled with the housework may bring about higher levels of work related stress; this in turn balances out the stress of men and women giving them the same level of work related stress.

The findings related to the second research question based on the difference between work related stress of single and married teachers show that as a whole there is not a significant difference between the two groups. But on the minor scales of socioeconomic based problems and time related stress the cases of the third and fourth research questions, there was a significant difference. Married teachers have a higher degree of job related stress based on socioeconomic problems compared with their single counterparts. In addition they also experience a higher level of stress caused by time issues compared to single teachers. Even though in past researches this was of lesser significance, this finding can be interpreted as such; the costly expenses of married life and the low income and benefits of teaching leads to a greater level of stress among married teachers. Providing for a standard sized family of two children and the expenses related to them can be very challenging, especially for a family in which only one parent is employed. This can be very hard for people in the teaching profession. Even if both parents are employed, there is always a substitute for financial difficulties that causes stress, in any way these affairs cause a higher level of job- related stress from a socioeconomic point of view in married teachers in relation to their single counterparts. Of course it shouldn't be forgotten that single teachers have problems of their own and it does not indicate a lack of socioeconomic stress for single teachers. In fact single teachers are in the crucial stage in which making a life for themselves, is in itself a financial burden.

Findings also show that the level of education has no relation to the amount of stress experienced by English teachers. Teachers with a range of different levels of education experience the same amounts of stress. For this point two reasons can be stated: First, on the basis of the variables that have been used in the research, it seems that the sources of stress for people with different levels of education are the same, thus the stress experienced by people from different educational backgrounds is the same. Second, on the contrary to the researcher's expectations, most of the English teachers had a high level diploma (54\%), and the others came from a variety of educational backgrounds. It may be for this reason that the state of work related stress at different levels of education has not yet been clarified. 
Another part of the findings showed that employment status of teachers have no significant correlation with their overall stress levels. This finding is contrary to our expectations. It would seem that teachers who don't have regular wages and a contract would experience higher levels of stress. It is not possible to say that regular employment from a socioeconomic standing for people who are in work or without work is the same, the reason must be found elsewhere.

limitations of the study

- The participants of the study were teachers of English in junior high schools and high schools of Kermanshah province and may not be generalizeable to other groups people.

- The sample was not homogeneous regarding level of education. Consequently, the results the results should be interpreted with caution.

- About $54 \%$ of participants had not specified their employment conditions and this might have affected the results.

Suggestions for further research

- It is recommended that teachers of other courses be included in the study so as to come up with better results.

- Each field has its own specific variables which may be considered as its stress generating factors. Therefore, it is recommended that these related variables be considered in other researches.

\section{REFERENCES}

[1] Booney,V., Miller, S., Humphreys, S., and Reynolds, F. (1989). Sources and Manifestation of Occupational Stress as Reported by Fulltime Teachers Working in a bio school, Journal of American Indian education Vol,28,(2) pp 21-31.

[2] Dolati, M. (2002). The relationship between job stress and marriage satisfaction and psychological health of men. Unpublished MA thesis: University of Tehran, Iran.

[3] Habibi, M. (2007). Sources of Teachers Stress. Journal of Psychology.Vol.56, pp. 75-91

[4] Kyriacou, C. (2001). Teacher stress: Directions for future research. Educational Review,53 (1), 27-35. Retrieved 17 March 2008 from: http://dx.doi.org/10.1080/00131910120033628

[5] Kyriacou, C. \& Sutcliffe, J. (1978). Teacher Stress: Prevalence, Sources and Symptoms. British Journal of Educational Psychology, 48, 159-167.

[6] kyriacou, C. \& Sutcliffe, J .(1978a). A Model of Teacher Stress. Educational Studies, Vol.4 (1), pp.1-6.

[7] Lewis. R. (1999). Teachers Coping with the Stress of Classroom Discipline. Social Psychology of Education, Vol.3(3), pp.155171

[8] Mitchell W.F. (2001). The Pathology of Unemployment, in W.F. Mitchell and E. Carlson (eds.), Unemployment: the Tip of the Iceberg, CAER/UNSW Press, Sydney, 11-32.

[9] Mitchell, K. J. (2005). Be Proactive: Including Students with Challenging Behavior in your Classroom. Intervention in School and Clinic. Vol. 40, (3), pp.188-191.

[10] Newman, J. E., \& Beehr, T. A. (1979). Personal organizational strategies for handling job stress: A review of research and opinion. Personnel Psychology, 32, 1-43.

[11] Pisanti, R. Galliards M \& Razino, S. (2003). Occupational Stress and Wellness among Italian Secondary School Teachers. Psychology and Health. 18(4), 523-536.

[12] Rasooli, M. (2003). An Investigation of Job Stress and Marriage Satisfaction among Male Police Officers. Unpublished MA thesis: University of Tehran. Iran

[13] Rezaee, E. R. (2002). An investigation of Stress amount in Iranian Teachers. Unpublished MA thesis: Shiraz University, Iran

[14] Rostaminai, T. (2000). Personality Types of A and B, and personal Factors Causing Stress among Education System Personnel. Unpublished MA thesis: Tarbait Modares University, Iran.

[15] Selye, H. (1993). History of stress concept. In L. Goldberger \& S. Breznitz (Eds.), Handbook of stress: Theoretical and clinical aspects (2nd Edition) (pp. 7-17). NewYork: The Free Press.

[16] Shinn, M., Rosario, M., Morch, H., \& Chestnut, D. E. (1984). Coping with job stress and burnout in human services. Journal of Personality and Social Psychology, 46, 864-876.

Habib Soleimani is a PhD candidate in TEFL in University of Isfahan. He was born in Kermanshah, Iran in 1976. Graduate from Tarbiat Moallem University of Tehran in TEFL, his interests are teaching methodology, Testing and Evaluation.

Ahmad Moinzadeh is associate Professor in the University of Isfahan. His interests are Teaching, Linguistics, and Syntax. 